\title{
Enhancing Holistic Identity through Yoga: Investigating Body-Mind-Spirit Interventions on Mental Illness Stigma across Culture-A Case Study
}

\author{
Elizabeth C. McKibben, Kin-Man Joshua Nan* \\ Department of Social Work and Social Administration \& Centre on Behavioral Health, the University of Hong Kong, Hong Kong \\ Email: *joshuanan@hku.hk
}

How to cite this paper: McKibben, E.C. and Nan, K.M.J. (2017) Enhancing Holistic Identity through Yoga: Investigating BodyMind-Spirit Interventions on Mental Illness Stigma across Culture-A Case Study. Open Journal of Nursing, 7, 481- 494. https://doi.org/10.4236/ojn.2017.74038

Received: January 3, 2017

Accepted: April 27, 2017

Published: April 30, 2017

Copyright $\odot 2017$ by authors and Scientific Research Publishing Inc. This work is licensed under the Creative Commons Attribution International License (CC BY 4.0).

http://creativecommons.org/licenses/by/4.0/ (c) (i) Open Access

\begin{abstract}
Objective: Mental illness stigma plagues many individuals with mental health issues such as depression. Labels attributed to the mentally ill focus on meeting diagnostic criterion, increase association with mental illness identities, and do not always promote greater wellbeing. Body-Mind-Spirit (BMS) interventions for depression address mental health without promoting stigmatizing labels. This study identifies how yoga can help to reduce mental illness stigma, and examines the effectiveness of a yoga intervention conducted by an expatriate in a cross-cultural context. Methods: This study took a qualitative research approach to examine the effectiveness of a four-week yoga class as an alternative Body-Mind-Spirit (BMS) intervention on participant Jenny (pseudonym) by a licensed yoga instructor and expatriate. Interpretive content analysis of post-intervention interviews, and subjective observational analysis throughout the yoga classes captured the movements of Body-Mind-Spirit as well as their impacts on the participant's perceptions of mental illness and the change through yoga practice. Results: Some specific themes from the participant's narratives were identified that could give light to the mechanism of change through yoga that stifles mental illness stigma, transforms identity, and enhances attention. Conclusion and implications for practice: Most notably, changes occurred through the physical to psychological axis of wellbeing, indicating some symbolic mechanism in yoga that facilitates the flow of information from the body to the mind. As Jenny's awareness of her body deepened, her association with a stigmatizing mental illness identity decreased. Although this study was limited in its generalizability, it shows an increased understanding of how identity is an important link between BMS interventions and mental illness stigma. Furthermore these findings suggest that there is a need for rigorous research in the effectiveness of yoga on mental ill-
\end{abstract}


nesses such as depression.

\section{Keywords}

Clay Art Therapy (CAT), Depression, Expressive Therapies Continuum, Alternative and Complementary Medicine, Emotion

\section{Introduction}

Mental illness stigma has profound effects upon the wellbeing of those who suffer from mental health problems. Identifying with a stigmatizing label can buffer negative in-group/out-group dynamics by promoting self-acceptance and normalization of otherness [1] [2]. However, identifying with mental illness identities may not have the same positive effects. Disclosure of mental illness identities emerges as an adaptive strategy, however does not bulwark relationships with non-mental illness identified individuals [3]. In other words, identifying with mental illness may create greater distance from 'normal' groups, and actually increase negative social interaction, stigma, and wellbeing [4]. In recovering from mental illness, redefining sense of self is an important factor in establishing wellness [5]. As such, identity is a key aspect in understanding experiences of recovery from mental health struggles. Since identifying with stigmatic labels can arise from mental illness diagnoses, treatment of mental illness that does not emphasize stigmatic labels could be beneficial for addressing redefinition of self-identity, self-awareness, and wellbeing for individuals with mental illnesses.

\subsection{Body Mind Spirit Approach}

The need for holistic approaches to mental health care has been clearly expressed in mental health research [6] [7] [8]. In particular, Body Mind Spirit (BMS) approaches to mental health care have received attention for their integrative approaches. Within this model there exist three interacting domains which contribute to the overall health of an individual: body, mind, spirit [9]. While conceptualizing what it means to have a healthy body is fairly simple, understanding the health of the mind and spirit is more complex. In this model the mind consists of psychological experiences (emotion, cognition, learning), while the spirit consists of relationship experiences (relationship with the self, people, higher power). While these three domains are understandable as separate entities, working within this model requires an understanding of the interaction of different domains. As such, many different therapies could fit into the BMS framework according to different domain combinations, and with emphasis on different aspects of the model.

Body. Much of yoga's popularity in recent years has been due to its benefits for the physical body [10]. Research shows that the physical practice of yoga is in itself a type of therapeutic approach. Yoga as a body-centered or body-based approach to therapy emphasizes the role of alignment, proprioception, and move- 
ment as a means of improving psychological function [11]. Although this meta-analysis posits that the "body" aspect of yoga can be an effective supplement to traditional psychotherapy, other research supports the significance of yoga's role in embodiment and symbolic processes [12] [13]. Broadly speaking, the physical aspects of yoga help to improve proprioception, a body awareness that also improves awareness of non-physical queues [14]. Reference [12] suggests that yoga increases awareness of physical sensations, and that this process of embodiment could explain the link between yoga and psychological health. Reference [13] further supports this claim in showing that awareness of body sensations helps facilitate self-monitoring and self-awareness. This research supports the idea that engaging in physical health practices may be able to promote awareness of a symbolic connection between body and mind. As a nonverbal means of communicating and understanding the self, yoga may serve to reduce threat responses such as self-shame in depressed individuals.

Mind. When considering the definition of "mind" it is important to consider both cognitive and emotional aspects of psychological ability. Cognition and emotion work interchangeably on psychosocial and biological levels [15], and thus inherently influence one another, particularly when considering mental health. Yoga has been shown to improve executive function, planning, and control abilities [16]. People who practice yoga are also shown to have greater emotional moderation due to increased attention resources [17]. As a mindfulness practice, yoga incorporates many awareness-focused aspects. The practice of yoga is fundamentally based on self-examination, which is a cognitive process that involves becoming aware of both physical and psychological experiences. Re-focusing of mental energy and cognitive reappraisal may help in moderating severe negative emotional responses. Women with major depressive disorder who completed an 8-week Hatha Yoga intervention were shown to have lower levels of depressive symptoms, and ruminate less on negative events [18]. In preventing emotional states that cloud the points of one's attention, yoga may aid in alleviating depressive symptoms by channeling cognitive and emotional energies into productive states that are advantageous for subjective well-being.

Spirit. In recent years, research has demonstrated that yoga may play a role in developing spiritual relationships. Spirituality, as a relationship construct, can be sought through relationships with a higher power, but also through the relationship with the self [19] [20] [21]. As a facet of spirituality, self-understanding seems to be an important for mental health care, stigma, and yoga [22]. Research shows that education about mental illness helps reduce experiences with stigma in certain populations [23], thus with further self-understanding, greater mental health can be attained. In a qualitative examination of different forms of yoga, participants were able to actualize their capacities, that is to say that yoga aided in promoting relationships with the self [24]. In promoting connection to sense of self, yoga has the capacity to counteract low self-esteem, which is closely associated with mental illness and mental illness stigma. Furthermore, self-efficacy serves as a predictor of physical, psychological and spiritual health [25]. As such, 
yoga provides a means for individuals to gain agency over their own health practices.

\subsection{Yoga for Mental Illness Stigma}

Evidently, previous research indicates that yoga as a health practice helps to target several different health domains. Through the physical practice of yoga, practitioners engage in embodiment, and explore the symbolic connections between the body, mind, and spirit. Yoga promotes self-awareness, facilitates psychologically productive attention, manages negative affective states, and promotes sense of connection. It appears that yoga maintains a holistic approach to healthcare that does not define health based on stigmatizing medical-model definitions. Despite these findings, there is little research that explores how yoga as a BMS intervention could impact perceptions of mental illness.

Previous research has indicated that yoga is efficacious in domains such as the body, the mind, and the spirit respectively [10] [17] [24]. While research has shown the benefits of yoga on these three domains, little research exists which explores yoga as a practice that combines or integrates these three areas of health. In order to pursue further understanding of yoga as a holistic health practice, understanding how yoga supports the BMS paradigm, and connects the three domains can assist in further research and application in clinical settings. Furthermore, no research has specifically addressed how yoga may impact mental illness stigma. As a holistic approach to mental healthcare, it seems logical that a multifaceted approach to healthcare may reduce stigmatic attitudes, and encourage positive self-perceptions in the face of mental illness.

\subsection{Purpose}

Exploring the ways in which yoga fits the BMS model could help to elucidate how holistic health practices effect perceptions of mental illness. Finding new methods of treatment that do not promote stigma could increase treatment adherence, and help-seeking behaviors in those who suffer from mental illness. Furthermore, understanding the relationships between the body, mind, and spirit in mental illness treatment can enable a deeper understanding of how mental illnesses such as depression manifest in all aspects of a person's life. In its totality, this research seeks to examine the potential mechanisms through which yoga can reduce stigma, and promote holistic health.

The data in this article comes from a master's dissertation that explored yoga as a BMS intervention from a cross-cultural perspective. The dissertation research was conducted by a licensed yoga instructor from the US with 4 years prior teaching experience. In that study, a 4-week clinical yoga intervention for depression was instituted for a single participant of Hong Kong Chinese background. This research sought to explore the potential for yoga to serve as a means of impacting experiences with mental illness stigma across cultures. The physical, psychological, and spiritual aspects of yoga as a BMS were explored in addition to yoga's effects of mental illness stigma. While yoga as a BMS inter- 
vention could potentially break down cultural barriers, the cross cultural nature of it could also exacerbate differences in cultural perceptions of mental illness.

\section{Hypothesis}

In order to address the aforementioned objectives, two hypotheses were developed which attempted to answer two essential questions: did yoga promote change in perceptions of mental illness and did yoga help facilitate the interconnectedness of the body, the mind and the spirit that benefitted wellbeing?

\section{Methods}

This study used qualitative research methods to investigate both the process and outcome of yoga as BMS intervention.

\subsection{Sampling \& Samples}

Due to the exploratory nature of this research, a specific clinical population with mood disorders was selected to investigate the effects of yoga. As a pilot study, a convenience sample with eight to twelve samples with diagnosed mild to moderate levels of depression and/or anxiety, aged 18 - 65, were aimed to be recruited between December $15^{\text {th }}, 2015$ and January 15 $5^{\text {th }}$, 2016. All participants were recruited by the collaborator - the OCD \& Anxiety Group Hong Kong, a newly established nongovernmental organization that did not have a specific site in which the research could be conducted. Extent of depressive symptoms and appropriateness of intervention were evaluated based on long-term behavioral observation from the OCD \& Anxiety Group Hong Kong. The founder of the organization, as the only administrative staff member, would take part by recruiting participants from the organization. The exclusion criteria of participants included those who were: 1) on psychoactive medication, 2) with or have suicidal tendency, or 3) unable or unsuitable to take part in group work setting. All measures were approved by the University of Hong Kong Research Ethics Committee.

Participants were recruited to participate in this research through both email and oral communication. An email was administered to the contact list at the OCD \& Anxiety Group HK, and the recruitment message was also read aloud at a group meeting. In order to reduce recruitment bias, the recruitment message limited potentially stigmatic wording, and emphasized the importance of "mental wellness" in this research. At the time of the recruitment email a specific location was unable to be reserved, and thus a nonspecific time was given to participants such that a specific time and location for the yoga class could be arranged to accommodate participant schedules. Ultimately, the project took place at the Centre on Behavioral Health at the University of Hong Kong. Participants indicated interest in the study via phone or email.

\subsection{Intervention}

In this pretest/posttest design study with post-intervention interview, partici- 
pants were asked to attend 4 consecutive weeks of once-weekly, hour-long yoga classes. The treatment lasted from January $23^{\text {rd }}$ and February $13^{\text {th }}$. After the completion of the preliminary forms (Beck Depression Inventory, Beck Anxiety Inventory, and Attitude towards Mental Illness Scale), participants were asked to engage in a 60-minute yoga class designed in the Hatha Yoga style. Each yoga class was conducted by a RYT-200 Yoga Alliance Certified Instructor with four years prior teaching experience. The classes were conducted in English, the second language of the participants. This style of yoga was selected as it is based in traditional yoga practices that most accurately reflect Body-Mind-Spirit philosophies. After each individual yoga class, participants engaged in a 10-minute semi-structured interview that explored their experiences with yoga, mental illness, and stigma. Similar interviews have been used to extract qualitative data from yoga practitioners' experiences [26]. This approach utilized formulaic, yet free-flowing questions to help elucidate potential mechanisms through which yoga has an impact on mental illness stigma.

Each of the standard Hatha yoga classes began with an opening guided meditation that focused on a different aspect of the yoga experience (Breath, Intention, Energy, Body and Mind). Following the opening meditation, participants engaged in a series of physical postures called asana, which are considered standard beginner postures, and include foreword folds, twisting, balance, and stretching. Once all of the postures had been completed, the instructor guided a final relaxation when participants scanned their bodies and minds, and engage in self-connection practices.

\subsection{Data Collection (Combined Qualitative Measures)}

Data of this study was collected via qualitative measures that included content from post intervention interviews, as well as observations from the processes of each yoga class. Although this research was originally intended to be a qualitative group yoga intervention, the eventual one-on-one yoga classes actually enabled the use of several different qualitative measures in the assessment of the participant's behaviors and experiences throughout her participation in the research.

After each yoga class, a one-on-one semi-structured interview was conducted in which the researcher asked questions to target the impacts of yoga. Specifically, these questions addressed experiences and perceptions of mood disorders, stigma, and yoga. The nature of the interview was meant to become progressively more intimate as rapport was developed between interviewer and interviewee. See Table 1 for a list of sample interview questions

Controlled observational analysis of behaviors throughout the yoga class enabled a greater understanding of in-the-moment experiences, and of the habits that participants may not be aware of, or able to articulate during interview. Observations were categorized broadly into physiological, psychological and spiritual reactions of the participant; these three domains reflect the framework of the intervention as a Body-Mind-Spirit Model. For each yoga session, the par- 
Table 1. Questions on mood disorders, stigma, and yoga.

\begin{tabular}{cl}
\hline \multicolumn{1}{c}{ Questions } \\
\hline 1 & What did you notice about yourself during the class? \\
3 & Would you recommend yoga to other people with anxiety or depression? Why? \\
4 & How do you think other people perceive taking yoga for depression and anxiety? \\
5 & How would you summarize your experience in the yoga class? \\
6 & How would you define relaxation? How does yoga help with anxiety and depression? \\
7 & Why do you think that people might not want to go to yoga for depression/anxiety? \\
8 & How do you motivate yourself to come to this yoga class? \\
9 & Now, how do you feel about anxiety and depression? \\
\hline
\end{tabular}

ticipants' physical reactions to specific postures, as well as her verbalizations of her inner experience are recorded and categorized to inform later data analysis.

\subsection{Data Analysis}

Audio-recorded transcripts of semi-structured interviews were assessed utilizing interpretive content analysis. Through content analysis, ambiguous statements were given structure by interpreting word choice in a variety of broad categories [27]. In the context of this research, the content was analyzed based on their applicability to two major constructs; body-mind-spirit, and stigma. Comments pertaining to the physical self were categorized under "body." Comments pertaining to the psychological self (ex. cognition, emotion) will be categorized under the "mind." Comments pertaining to self-awareness or self-connection will be categorized under the "spirit."

The themes of "body," "mind," and "spirit" as categorizations were derived from controlled observation during the yoga class and were adopted for data interpretation. Despite the fact that interpretive content analysis from interviews and controlled observation during yoga practice were analyzed separately, the results of the analyses were triangulated by comparing the contents that were derived from each data source and between researchers. The combined process outcome data collection and analyses methods could function to examine the effectiveness of yoga on the designated objectives and provide facts to how yoga could potentially impact body-mind-spirit that could expand and give hints to the mechanism of change in yoga.

\section{Results}

\subsection{Sample}

After the recruitment period completed, five participants showed interest in the study and a preliminary phone-interview was conducted, after which three out of five prospective participants wished to continue with the study. The participant did not complete demographic data, for she was not willing to disclose 
personal particulars and specific information about herself, for fear that might label her as mentally ill, thus suggesting mental illness stigma. She appeared to be between 50 and 65 years of age, Hong Kong Chinese, of medium height and thin figure. The participant did not attend one of the four required sessions, and thus there is only data from three yoga classes.

\subsection{Controlled Observational Analysis}

Controlled observational analysis was measured across the three domains of Body, Mind, and Spirit, which are represented in Table 2. In the aspect of Mind, through each of the sessions, the participant showed progress in concentration, higher frustration and disturbance tolerance, and decline in trivial preoccupations. In the aspect of Body, the participant showed gradual mastery of physical balance, higher endurance and flexibility in making different yoga postures, improved breathing practice, and a sustained siting posture for meditation. In the aspect of Spirit, the participant had progress from not showing any distinct change, to the awareness of focusing experience and mindful practice throughout yoga practice. Overall, the combined observational analyses exhibited that the participant could psychologically attune to the routine of a yoga practice. It was speculated that if more sessions were available, there could have been be a clearer demonstration of the flow of changes in state of being. Additionally, the participant demonstrated improvement in balance, flexibility, and maintenance of postures.

Table 2. Experiences with mind, body, and spirit during yoga class.

\begin{tabular}{|c|c|c|c|}
\hline Session & Mind & Body & Spirit \\
\hline 1 & $\begin{array}{l}\text { - Flustered upon entering the yoga classroom } \\
\text { - Preoccupation with the orientation of her yoga } \\
\text { mat, and cleaned the mat twice before beginning } \\
\text { the class } \\
\text { - Continually asking questions despite being told to } \\
\text { - Frain, showing skepticism } \\
\text { was" }\end{array}$ & $\begin{array}{l}\text { - } \text { Frequent opening of the eyes } \\
\text { - Requiring a bathroom break after } 30 \text { minutes } \\
\text { - Difficulty balancing } \\
\text { - Holding postures longer than instructed to }\end{array}$ & - No indication \\
\hline 2 & $\begin{array}{l}\text { - Cleaned her yoga mat twice prior to the } \\
\text { beginning of class } \\
\text { - Distracted and disengaged from the yoga practice } \\
\text { for the first } 10 \text { minutes } \\
\text { - Asked fewer questions during the class and } \\
\text { showed greater concentration }\end{array}$ & $\begin{array}{l}\text { - Improvement in balancing during vriksasana } \\
\text { - Asked for a restroom break in the middle of } \\
\text { class because "otherwise [she] won't be able } \\
\text { to relax" } \\
\text { - Deeper breath } \\
\text { - Able to sit silently and stilly for almost } 3 \mathrm{x} \text { as } \\
\text { long as the initial meditation }\end{array}$ & $\begin{array}{l}\text { - Improved self-awareness } \\
\text { and connection to her } \\
\text { personal experience, "I } \\
\text { do better when I am more } \\
\text { focused" }\end{array}$ \\
\hline 3 & $\begin{array}{l}\text { - Not perplexed or flustered upon arriving } \\
\text { - Cleaned the yoga mat twice } \\
\text { - Increased concentration and focus - only made } \\
\text { one comment throughout the } 60 \text { minute class }\end{array}$ & $\begin{array}{l}\text { - } \text { Much deeper and more consistent breathing } \\
\text { - } \\
\text { - } \text { experience } \\
\text { - Able to hold postures for longer } \\
\text { - Improvement in balance and flexibility }\end{array}$ & $\begin{array}{l}\text { More mindful } \\
\text { throughout the practice }\end{array}$ \\
\hline
\end{tabular}




\subsection{Interpretative Content Analysis}

Interpretive content analysis measured interview responses in terms of relevance to the body-mind-spirit paradigm, and to mental illness stigma, which are represented in Table 3. It can be seen that in all domains (body, mind, and spirit) the participant experienced change from a concrete and fixed self-concept to invoking change in her mental health behaviors and generating a sense of selfefficacy that could potentially helped to eliminate stigmatic attitudes.

\section{Discussion}

The initial aims of this study were to further explore experiences with stigma in the context of BMS interventions. Despite the fact that qualitative analyses did not directly demonstrate changes in mental illness stigma after the yoga intervention, notable changes in personal insight were observed. After the intervention Jenny attested to having improved attention resources, emotional control, and a deep interest in the pursuit of self-actualization. Most significantly, after the intervention Jenny exhibited less identification with stigmatizing labels associated with mental illness. It is possible that the discovery of new aspects of herself enabled Jenny to cultivate a greater sense of efficacy, and confidence in herself.

Table 3. Experiences with yoga and perceptions of mental illness and stigma.

\begin{tabular}{|c|c|c|c|}
\hline Session & Body, Mind, Spirit & $\begin{array}{c}\text { Qualitative Analysis of Change on } \\
\text { Mental Health }\end{array}$ & Stigma \\
\hline 1 & $\begin{array}{l}\text { Mind } \\
\text { "I'm an A-type personality" (i.e. faster and stronger } \\
\text { response to stressors) } \\
\text { "I cannot just relax and let it be" } \\
\text { Spirit } \\
\text { "the class was not very satisfying for me" }\end{array}$ & $\begin{array}{l}\text { Mind } \\
\text { Slight change in disturbance of negative } \\
\text { moods from beginning to end of practice } \\
\text { Body - Mind } \\
\text { Initial attending to body/mind } \\
\text { Diversified self-concept }\end{array}$ & $\begin{array}{l}\text { Demonstrated no stigmatic } \\
\text { attitudes } \\
\text { "I would definitely tell a friend } \\
\text { that I am doing yoga for my } \\
\text { depression" }\end{array}$ \\
\hline 2 & $\begin{array}{l}\text { Body } \\
\text { "if you don't feel the stretch, you don't feel the } \\
\text { relaxation" } \\
\text { relaxation considered as a physical concept } \\
\text { Mind } \\
\text { "I feel frustrated, it is difficult [to overcome depression]" } \\
\text { "to make change I need 'motivation, determination, and } \\
\text { hard work" } \\
\text { Spirit } \\
\text { "I will do anything to have a more joyful, relaxed life" }\end{array}$ & $\begin{array}{l}\text { Body-Mind } \\
\text { Improved understanding of interconnected } \\
\text { relationship of body-mind } \\
\text { Spirit } \\
\text { Increased enjoyment of and satisfaction in } \\
\text { yoga practice } \\
\text { Discovery of a way to achieve } \\
\text { self-fulfillment }\end{array}$ & $\begin{array}{l}\text { Discovery of a potential way to } \\
\text { actively eliminate stigma via yoga } \\
\text { practice }\end{array}$ \\
\hline 3 & $\begin{array}{l}\text { Body } \\
\text { "after experiencing the stretching I learn a bit how to } \\
\text { relax" } \\
\text { "focusing on my body helps to make my mind and body } \\
\text { to relax" } \\
\text { noted improvement in sleep quality } \\
\text { Mind } \\
\text { "I am quite unable to contain my emotion" } \\
\text { "I will try to take a breath when I feel this [highly } \\
\text { emotionally reaction] again" } \\
\text { Spirit } \\
\text { "I feel great" }\end{array}$ & $\begin{array}{l}\text { Body-Mind } \\
\text { Continual strengthened understanding of } \\
\text { interconnected-ness of body-mind }\end{array}$ & $\begin{array}{l}\text { An improved sense of } \\
\text { self-efficacy as a possible means } \\
\text { of eliminating a stigmatic attitude }\end{array}$ \\
\hline
\end{tabular}




\subsection{Mental Illness Stigma \& Process of Change through Yoga}

The participant demonstrated stigmatic attitudes towards mental illness in her repetitive statements that her personality and identity were defined by her mood problem. However, the researchers did not provide space for the participant to fully explore and express the contents of mental illness stigma. From her first session onwards Jenny closely associated her diagnoses of depression and anxiety with her personality. Jenny seemed to construct an identity based on a psychiatric diagnosis. Jenny's tenacity in repeating her diagnoses is also mirrored in the language she uses to describe her abilities. Immediately after discussing this inability she reverts to explaining that her "A-type" personality justifies why she "cannot relax." While research suggests that identity selection can buffer negative in-group/out-group dynamics [1], identifying with a mental illness identity may increase association with other mental illness sufferers and increase also negative social interaction and stigma [4], Jenny's acceptance of her mental illness may also inhibit her access to social support that is not in a mental-health centered setting.

Initially, her imposed mental illness identity made it difficult for her to accept her capacities beyond the symptoms that define anxiety and depression (in this case, stress or the inability to relax). Through a physical practice she began to dissociate her physical capacities from her psychological identity. Initially, Jenny could not define what the word "relaxed," meant to her; however after the series of yoga classes she began to define relaxation as a physical sensation. As she gained more access to understanding her physiological experience, her preoccupation with her "A-type" personality, and depressed identity began to decrease. It may be that her body became the tool through which she could access a greater psychological self-understanding, although not necessarily being aware of this phenomenon. As such, the practice of yoga as a BMS intervention uses the physical self as a symbolic tool for accessing greater psychological resources.

Throughout the three yoga classes Jenny exhibited a change in her overall ability to concentrate on present moment tasks. Her ability to concentrate on her physical experience enabled her to continue focusing, and reap greater benefits from the yoga practice. Not only did Jenny's concentration on her physical self-improve during the research, her psychological attention also shifted. During the final post-yoga interview Jenny no longer fixated on her "depressed and anxious personality." While she may not be aware of it, this phenomenon reflects a decrease in stigmatizing attitudes towards mental illness. She reduces her association with a psychiatric label, and since psychiatric labeling has been shown to increase stigma, she may be showing signs of decreased stigma [28].

\subsection{Mind-Body Connectivity}

From the first to the last session, the participant showed increased understanding of how the experience of physical stretching enables physical relaxation, and how focusing on the body enables psychological relaxation. She also progressively demonstrated less preoccupation from her depressed and anxious moods 
with higher levels of motivation to take part in yoga practice and focus on the process. The gradual understanding of how the body and the mind are interconnected and the re-experiencing of positive emotional change via physical exercise is significant. These experiences can facilitate the participant to develop new understanding in mind - body connectivity. This new understanding signifies a new way of emotional learning that physical exercise, such as yoga, can positively impact mood. The research results to a certain extents confirms the notion that notion that cognition - emotion interrelation might not necessarily originate from only the cognitive change that influences change on emotion. As other forms of body-based therapies (e.g. arts therapy), the example of the impact of yoga practice on emotion and cognition supports the bottom-up approach that change of bodily state (e.g. physical relaxation) can impact emotion and subsequently cognition [29] [30].

\subsection{Spirituality}

While the participant did not explicitly discuss her experience with spirituality may suggest two possible explanations. First, spirituality is an abstract idea that individuals may not have the awareness to focus, explore and express about it. Second, the transition of the participant from not having any satisfaction from the yoga, to motivation to find satisfaction from yoga, to feeling satisfied from the yoga class, suggests that she demonstrated a progressively strengthening of connection on a personal level. The process and success in making meaning of life and the demonstration of personal satisfaction are significant exhibition of the facets of spirituality [19] [20]. The experience with yoga can potentially give the client the belief in her ability to find or build up new meaning in life.

\subsection{Yoga Practice Research in a Cross-Cultural Setting}

Many difficulties arose throughout the course of the research. For example, difficulties affecting the sample size, recruitment processes, protocol adherence and conducting the research in English (which is a second language for the participants). The language barriers may have impacted the influence of specific nuanced language queues and prompts in the yoga class. In further research it will be tantamount to have a third party to serve as a co-facilitator who can interpret cultural and contextual queues present in both languages.

Additionally, while yoga may help to buffer cross cultural differences by accessing the BMS paradigm, underlying conflicting beliefs about mental illness could have hindered the success of the project. In particular, it is important to note that differences between eastern and western conceptualization of mental illness are significant. It is then possible that there was a mutual challenge in interpreting what the researcher or participant truly meant when talking about depression or anxiety.

Despite these challenges, this research demonstrates a very important principle of conducting cross-cultural research on sensitive topics. It demonstrates the need for contextualization and mutual understanding amongst both parties. 


\section{Conclusions and Limitations}

Despite the brevity of intervention, the BMS intervention in yoga practice demonstrated the effectiveness in helping the participant in at least two major ways. First, yoga practice helped Jenny to positively focus on body-mind-spirit wellbeing through constant practice of yoga. The results of the practice also encouraged her to differentiate from the identity of a mental illness patient and associate herself with the "normal" pool of people. Second, the required intense attention during yoga practice as an attention-promoting behavior or focusing practice could serve as a mechanism to help divert stigmatic attitudes toward mental illness. It is unclear what the mechanism is that explains her vocalized shifts in attention and rumination, however, according to attention constructs and previous research on yoga [31].

While this research cannot conclusively state that yoga serves to reduce mental illness stigma, it has uncovered some of the mechanisms through which body-mind-spirit practices have potential to promote holistic self-understanding and wellbeing. Yoga reallocates attention resources outside of psychological preoccupations and into the physical self, thereby increasing and diversifying self-conceptualizations. In so doing, a more holistic sense of self is created, which diverts stigmatic attitudes towards mental illness, and reduces the power a mental illness diagnosis has over an individual's sense of identity. By connecting with one's physiological resources, conceptualization of psychological resources can expand. It is, however, significant, in this case study that the relationship between the body and the mind in yoga clearly has an important role in facilitating attention resources that deems further investigation.

Since the power of this study is limited by the small sample size, generalization of results should be at the focus of future research. Future research could integrate qualitative and quantitative methods with a larger sample size. In so doing, a clearer portrait can be painted of the mechanisms underlying the various benefits of a yoga practice.

\section{References}

[1] Szabo, A. and Ward, C. (2015) Identity Development during Cultural Transition: The Role of Social-Cognitive Identity Processes. International Journal of Intercultural Relations, 46, 13-25.

[2] Kranke, D., Jackson, S.E., Taylor, D.A., Landguth, J. and Floersch, J. (2014) "I'm Loving Life”: Adolescents' Empowering Experiences of Living with a Mental Illness. Qualitative Social Work, 14, 102-118. https://doi.org/10.1177/1473325013510545

[3] Ilic, M., Reinecke, J., Bohner, G., Rottgers, H., Beblo, T., Driessen, M., Frommberger, U. and Corrigan, P.W. (2014) Managing a Stigmatized Identity-Evidence from a Longitudinal Analysis About People with Mental Illness. Journal of Applied Social Psychology, 44, 464-480. https://doi.org/10.1111/jasp.12239

[4] Cruwys, T. and Gunaseelan, S. (2016) “Depression Is Who I Am": Mental Illness Identity, Stigma and Wellbeing. Journal of Affective Disorder, 189, 36-42.

[5] Thomas, K.A. and Rickwood, D.J. (2016) One Woman's Journey of Recovery from Mental Illness-Hopes, Back-Up Plans, Rebuilding Self and Service Support. Qualita- 
tive Social Work, 15, 501-517. https://doi.org/10.1177/1473325015593173

[6] Klausen, R.K., Karlsson, M., Haugsgjerd, S. and Fagerjord Lorem, G. (2016) Motherhood and Mental Distress: Personal Stories of Mothers Who Have Been Admitted for Mental Health Treatment. Qualitative Social Work, 15, 103-117. https://doi.org/10.1177/1473325015584981

[7] Mathew, S.J. (2012) Review of Treatment Resistant Depression: A Roadmap for Effective Care. Journal of Psychiatric Practice, 18, 388-389. https://doi.org/10.1097/01.pra.0000419824.47043.57

[8] Nebelkopf, E. and Wright, S. (2011) Holistic System of Care: A Ten-Year Perspective. Journal of Psychoactive Drugs, 43, 302-308. https://doi.org/10.1080/02791072.2011.628922

[9] Chan, C., Ho, P.S. and Chow, E. (2001), A Body-Mind-Spirit Model in Health: An Easter Approach. Social Work and Health Care, 34, 261-282. https://doi.org/10.1300/J010v34n03_02

[10] Quilty, M.T., Saper, R.B., Goldstein, R. and Khalsa, S.B.S. (2013) Yoga in the Real World: Perceptions, Motivators, Barriers, and Patterns of Use. Global Advances in Health and Medicine, 2, 44-49. https://doi.org/10.7453/gahmj.2013.2.1.008

[11] Shapiro, L. (2013) Yoga Based Body Psychotherapy: A Yoga Based and Body Centered Approach to Counseling. International Body Psychotherapy Journal, 12, 42 55.

[12] Impett, E.A., Daubenmier, J.J. and Hirschman, A.L. (2006) Minding the Body: Yoga, Embodiment, and Well-Being. Sexuality Research \& Social Policy, 3, 39-48. https://doi.org/10.1525/srsp.2006.3.4.39

[13] Pagis, M. (2009) Embodied Self-Reflexivity. Social Psychology Quarterly, 72, 265 283. https://doi.org/10.1177/019027250907200308

[14] Fiori, F., David, N. and Aglioti, S.M. (2014) Processing of Proprioceptive and Vestibular Body Signals and Self-Transcendence in Ashtanga Yoga Practitioners. Frontiers in Human Neuroscience, 8, 734. https://doi.org/10.3389/fnhum.2014.00734

[15] Bush, G., Luu, P. and Posner, M.I. (2000) Cognitive and Emotional Influences in Anterior Cingulate Cortex. Trends in Cognitive Sciences, 4, 215-222.

[16] Gothe, N., Pontifex, M.B., Hillman, C. and McAuley, E. (2013) The Acute Effects of Yoga on Executive Function. Journal of Physical Activity \& Health, 10, 488-495. https://doi.org/10.1123/jpah.10.4.488

[17] Menezes, C.B., Dalpiaz, N.R., Rossi, N.T. and De Oliveira, A.A. (2015) Yoga and the Interplay between Attentional Load and Emotion Interference. Psychological Reports, 117, 271-289. https://doi.org/10.2466/28.02.PR0.117c16z1

[18] Kinser, P.A., Bourguignon, C., Whaley, D., Hauenstein, E. and Taylor, A.G. (2013) Feasibility, Acceptability, and the Effects of Gentle Hatha Yoga for Women with Major Depression: Findings from a Randomized Controlled Mixed-Methods Study. Archives of Psychiatric Nursing, 27, 137-147.

[19] Cook, C., Breckon, J., Jay, C., Renwick, L. and Walker, P. (2012) Pathway to Accommodate Patients' Spiritual Needs. Nursing Management, 19, 33-37. https://doi.org/10.7748/nm2012.05.19.2.33.c9059

[20] Peteet, J.R. and Balboni, M.J. (2013) Spiritualty and Religion in Oncology. CA: $A$ Cancer Journal for Clinicians, 63, 280-289. https://doi.org/10.3322/caac.21187

[21] Zinnbauer, B.J., Pargament, K.I. and Scott, A.B. (1999) The Emerging Meanings of Religiousness and Spirituality: Problems and Prospects. Journal of Personality, 67, 889-919. https://doi.org/10.1111/1467-6494.00077 
[22] Mehta, S. and Farina, A. (1997) Is Being "Sick" Really Better? Effect of the Disease View of Mental Disorder on Stigma. Journal of Social and Clinical psychology, 16, 405-419. https://doi.org/10.1521/jscp.1997.16.4.405

[23] Conner, K.O., McKinnon, S.A., Ward, C.J., Reynolds, C.F. and Brown, C. (2015) Peer Education as a Strategy for Reducing Internalized Stigma among Depressed Older Adults. Psychiatric Rehabilitation Journal, 38, 186-193. https://doi.org/10.1037/prj0000109

[24] Burde, J.K. and Rao, A.H.S. (2011) Self-Actualization from an Eastern PerspectiveA Preliminary Exploration. Psychological Studies, 56, 373-377. https://doi.org/10.1007/s12646-011-0097-7

[25] Lee, E.O. (2007) Mind-Body-Spirit Practice and Perceived Self-Efficacy for Mental Health Promotion: An Exploratory study. International Journal of Mental Health Promotion, 9, 35-47. https://doi.org/10.1080/14623730.2007.9721841

[26] Suneetha, K. (2014) Meditative Replay of Troubling Life Events and Transformation in Practitioners of Yoga and Meditation: A Pilot Study. Asia Pacific Journal of Counseling and Psychotherapy, 5, 172-178. https://doi.org/10.1080/21507686.2014.948560

[27] Ginger, C. (2006) Interpretive Content Analysis. In: Yanow, D. and Shwartz-Shea, P., Ed., Interpretation and Method: Empirical Research Methods and the Interpretive Turn, Sharpe, New York.

[28] Ben-Zeev, D., Young, M.A. and Corrigan, P.W. (2010) DSM-V and the Stigma of Mental Illness. Journal of Mental Health, 19, 318-327.

https://doi.org/10.3109/09638237.2010.492484

[29] Siegal, D.J. (2009) Emotion as Integration: A Possible Answer to the Question, What Is Emotion? In: Fosha, D., Siegal, D.J. and Solomon, M., Eds., The Healing Power of Emotion: Affective Neuroscience, Development, and Clinical Practice, W.W. Norton \& Co., New York, London.

[30] Schore, A.N. (2015) Affect Regulation and the Origin of the Self: The Neurobiology of Emotional Development. Reprint Edition, Routledge, Abingdon-on-Thames.

[31] Prakash, R., Dubey, I., Abhishek, P., Gupta, S.K., Rastogi, P. and Siddiqui, S.V. (2010) Long-Term Vihangam Yoga Meditation and Scores on Tests of Attention. Perceptual and Motor Skills, 110, 1139-1148. https://doi.org/10.2466/pms.110.3c.1139-1148

\section{Submit or recommend next manuscript to SCIRP and we will provide best service for you:}

Accepting pre-submission inquiries through Email, Facebook, LinkedIn, Twitter, etc. A wide selection of journals (inclusive of 9 subjects, more than 200 journals)

Providing 24-hour high-quality service

User-friendly online submission system

Fair and swift peer-review system

Efficient typesetting and proofreading procedure

Display of the result of downloads and visits, as well as the number of cited articles

Maximum dissemination of your research work

Submit your manuscript at: http://papersubmission.scirp.org/

Or contact ojn@scirp.org 